\title{
De Aristóteles a las políticas públicas de la felicidad en el Perú. Disquisiciones desde un estudio en dos estratos
} sociales

\section{From Aristotle to happiness in public policy in Peru. Reflections from a study across two strata}

\author{
Franklin Ibáñez ${ }^{1}$ \\ Universidad del Pacífico. Lima, Perú \\ fe.ibanezb@up.edu.pe \\ ORCID 0000-0002-1648-6362 \\ Javier Zúñiga ${ }^{3}$ \\ Universidad del Pacífico. Lima, Perú \\ zuniga_jj@up.edu.pe \\ ORCID 0000-0001-5563-3962
}

Pedro Mateu ${ }^{2}$

Universidad del Pacífico. Lima, Perú

pf.mateub@up.edu.pe

ORCID 0000-0001-8759-9244

Enrique Vásquez ${ }^{4}$

Universidad del Pacífico. Lima, Perú

vasquez_ee@up.edu.pe

ORCID 0000-0002-3873-9180

Citar como: Ibáñez, F., Mateu, P., Zúñiga, J. y Vásquez, E. (2020). De Aristóteles a las políticas públicas de la felicidad en el Perú. Disquisiciones desde un estudio en dos estratos sociales. Desde el Sur, 12(2), pp. 501-523.

\section{RESUMEN}

En las últimas décadas la felicidad se ha convertido en un tema importante para diversas disciplinas y, desde allí, ha comenzado una reflexión por su posible aplicación a las políticas públicas. Un equipo interdisciplinario de investigadores ha recogido las ideas más comunes relacionadas con la felicidad en el Perú a partir de entrevistas a los

1 Doctor en Filosofía por la Pontificia Universidad Gregoriana (Italia) y Magíster por la Pontificia Universidad Católica del Perú. Profesor en la Universidad del Pacífico, la Pontificia Universidad Católica del Perú y la Universidad Nacional Mayor de San Marcos. Ha recibido reconocimientos en investigación, docencia y responsabilidad social universitaria.

2 Profesor del Departamento Académico de Economía de la Universidad del Pacífico y miembro del Centro de Investigación de la Universidad del Pacífico. Ph.D. en Evaluación y M.Sc. en Estadística Aplicada por la Universidad de Western Michigan, EE. UU. Desde el 2019 es revisor de la revista académica Happiness Studies.

3 Doctor en Matemáticas por la Universidad de Minnesota (2007) y licenciado en Matemáticas por la Pontificia Universidad Católica del Perú (2001). Profesor del Departamento de Economía de la Universidad del Pacífico y miembro del Centro de Investigación (desde 2011). Ha sido investigador en la Universidad de Purdue (2009-2011) y en el Instituto Tata de Investigación Fundamental (2008-2009).

4 Economista por la Universidad del Pacífico, M. Sc. en políticas públicas y Ph. D. en política por la Universidad de Oxford (Inglaterra). Consultor de organismos internacionales, cooperación internacional y ONG. Especialista en políticas y programas de alivio de la pobreza, inversión social y derechos de los niños y adolescentes. Profesor principal del Departamento de Economía e investigador senior del Centro de Investigación de la Universidad del Pacífico. 
jefes de hogar de los distritos más pobres y más ricos del país. El presente texto examinará tales resultados a partir de la teoría de Aristóteles, a fin de brindar fundamentos teóricos para posibles políticas públicas. La teoría clásica aristotélica o eudaimonista permite distinguir entre concepciones más superficiales y profundas de la felicidad. Se concluye que políticas asociadas a la felicidad promueven una vida humana plena que comprende acceso a la salud, la educación, el empleo y la promoción de la solidaridad ciudadana. Se desmitifica también la idea de que los pobres solo necesitan o desean dinero para ser felices.

\section{PALABRAS CLAVE}

Felicidad, políticas públicas, bienestar subjetivo, Aristóteles, políticas de felicidad

\section{ABSTRACT}

Over the last decades, happiness has become an important subject addressed by several disciplines, leading to reflection on its possible application in public policies. An interdisciplinary team of researchers has brought together the most common notions associated with happiness in Peru, based on interviews with heads of households in the poorest and the wealthiest districts in the country. This paper will examine those findings from the Aristotelian theoretical framework, in order to provide a theoretical basis for possible public policies. The classical Aristotelian or Eudaimonist theory distinguishes between superficial and more profound conceptions of happiness. This article asserts that policies oriented to happiness foster full lives that include access to health, education and employment, and the encouragement of citizen solidarity, while demythologizing the idea that poor people only need or want money in order to be happy.

\section{KEYWORDS}

Happiness, public policies, subjective wellbeing, Aristotle, happiness policies

\section{Introducción}

Por un lado, el progresivo interés en la felicidad desde las más diversas disciplinas académicas, desde la psicología hasta la economía, se traduce en la proliferación de definiciones y métricas, así como en un intenso 
debate. Veenhoven (1997) y Prasoon y Chaturvedi (2016) reseñan la imponente bibliografía entre tan solo dos décadas de distancia, y pese a la confusión y superposición de términos: bienestar subjetivo, florecimiento, satisfacción vital. Por otro lado, un crecimiento semejante se muestra en la preocupación por utilizar la felicidad como fin de las políticas públicas. Desde que en 1972 el Reino de Bután se embarcó en la concreción de la felicidad como principal indicador del bienestar social (Ura, Alkire y Tshoki, 2012), pasaron casi 50 años hasta que en 2011 las Naciones Unidas adoptasen la felicidad entre las metas sociales que sus Estados miembros deben promover (ONU, 2011). La OCDE se aventuró casi simultáneamente (OCDE, 2013). Venezuela creó el Viceministerio para la Suprema Felicidad Social del Pueblo en 2013, mientras que Emiratos Árabes Unidos fue más lejos y creó un ministerio para su promoción en 2016.

Conviene preguntarse si existe o debería existir una concepción normativa de la felicidad detrás de este efervescente interés. ¿Qué ha sucedido con la eudaimonia? ¿La legítima preocupación contemporánea por ella incluye un marco teórico que permita separar el trigo de la paja? ¿Cómo recuperar elementos éticos sustantivos a fin de evitar llamar felicidad a cualquier cosa? El presente texto constituye un ejercicio teórico para darle sustento al posible diseño e implementación de políticas públicas. Un equipo interdisciplinario de investigadores se embarcó en la empresa de comprender la felicidad en los extremos de la pirámide social del pueblo peruano con la esperanza de que sus hallazgos pudieran eventualmente inspirar políticas públicas. Uno de los productos es el texto que acá se ofrece para discutir los hallazgos contra el marco teórico aristotélico, todavía vigente para el estudio de la felicidad.

El artículo aprovecha la data recogida por la «Encuesta de medición de los índices de felicidad, pobreza multidimensional y valores en dos Perús», realizada por el Centro de Investigación de la Universidad del Pacífico en 2017, denominada en adelante Encuesta FPV. La muestra se concentró en los cinco distritos más y los cinco menos privilegiados económicamente del Perú según el mapa de pobreza monetaria del Instituto Nacional de Estadística e Informática (INEI, 2015) ${ }^{5}$. La muestra fue conformada por 406 y 537 jefes de hogar, respectivamente. El INEI, además, proporcionó las muestras aleatoriamente y los parámetros para que los entrevistados fueran representativos de las poblaciones en términos de sexo y edad. De este modo, se incluye tanto hombres y mujeres como jóvenes, adultos y adultos mayores.

5 El Perú se divide en 25 regiones, cada una de ellas en provincias y estas a su vez en distritos. El mapa consideró un total de 1943 distritos (INEI, 2015). 
Pero la diferencia fundamental reside en pertenecer a los distritos más pobres o más ricos del país. Aunque se utilice construcciones sustantivas semejantes para referirnos a las personas entrevistadas a lo largo del texto, siempre se referirán a los jefes de hogares pobres o ricos. Ambos grupos constituyeron tal vez no una sino dos muestras, pues reflejan, en varios aspectos, dos mundos paralelos. Sucede así porque las sociedades latinoamericanas poco caso han hecho de la sabia advertencia de Platón. El célebre filósofo sostenía que si la riqueza se concentrase en pocos, como suele pasar, no existirá uno sino dos Estados: el de los ricos y el de los pobres, por lo cual resulta impropio hablar de un solo país ${ }^{6}$. Dado que los entrevistados representan solo a los extremos socioeconómicos, no sería prudente inferir posibles políticas de la felicidad para todo el país. Pero al menos sí parece factible derivar reflexiones que incumben a la felicidad de aquellos grupos.

\section{Cuestiones normativas sobre quién define la felicidad: entre el filósofo rey y "pan y circo»}

Indagar sobre la felicidad plantea una cuestión previa. ¿Quién la define? ¿Quién detenta el conocimiento y poder adecuados para determinar lo que es o no felicidad? Si la investigación procura su correlato en políticas públicas para sociedades democráticas - o sociedades que aspiran a ser democráticas-, es menester no solo fundamentar definiciones, sino también legitimar su método de obtención. ¿Quién está autorizado a precisar el significado de la felicidad? Por ejemplo, ¿solo los académicos e intelectuales, o solo las masas?

Por un lado, los filósofos griegos investigaron la cuestión por la felicidad o la mejor vida posible. Aristóteles, sin duda, ocupa un lugar relevante en dicha tradición. Sin embargo, ¿solo los filósofos están capacitados para el gobierno como creía Platón (1988)? El filósofo rey corre el riesgo de considerar que solo él ha hallado la mejor manera de vivir. Como déspota ilustrado, desea compartirla, cuando no imponerla, al resto del pueblo. Él y su grupo selecto saben lo que en verdad les conviene a las personas. Han visto la luz, han salido de la caverna en alusión a la célebre alegoría platónica. Por analogía, académicos y tecnócratas contemporáneos heredan inconscientemente el desafío de no obnubilarse por razonamientos monológicos y sus técnicas tan especializadas como exclusivas.

6 «Cada uno de esos Estados no es un Estado sino muchos. Son dos como mínimo, con una enemistad mutua: el Estado de los pobres y el de los ricos. Y en cada Estado hay muchos Estados; si los tratas como a uno solo, te equivocarás de cabo a rabo» (1988, p. 206 [422e8423a3]). Se utiliza el citado clásico entre corchetes. 
Por otro lado, frecuentemente el vulgo no sabe lo que quiere. Busca desesperadamente aquello que cree que lo hace feliz. Pero desatina, pues desconoce su propia naturaleza. Su felicidad no se iguala a la satisfacción de sus deseos y necesidades animales ${ }^{7}$. Sin embargo, el pueblo a veces se conforma con panem et circenses. La metáfora sigue vigente - tal vez actualizada por cervezas y fútbol, por ejemplo-y continúa siendo explotada por regímenes populistas de derecha e izquierda.

Frente a tales demandas y peligros, se ha recorrido una vía intermedia. Frente al elitismo académico y tecnócrata, la democracia significa valorar las opiniones divergentes y plurales; dar voz a los interlocutores y afectados; tomarse en serio sus posiciones y argumentos. Se requiere escuchar $y$ evaluar las opiniones de los ciudadanos reales, aunque también sea cierto que, como aconseja el Estagirita, «quizá es inútil examinar a fondo todas las opiniones, y basta con examinar las predominantes o que parecen tener alguna razón» (1998, p. 135 [1095a28-30]) ${ }^{8}$. La encuesta ofrece la ventaja de sintetizar significados y expectativas comunes en los extremos sociales del Perú. Además, frente a una mirada condescendiente y acrítica sobre cualquier forma de felicidad, el artículo analiza los resultados a partir del trasfondo aristotélico. Concretamente se confronta las opiniones de las personas entrevistadas con la teoría eudaimonista expuesta en la Ética nicomaquea. Tal visión permite distinguir formas más normativamente pertinentes de felicidad.

Aunque no existe espacio acá para desarrollar a fondo la siguiente idea, conviene señalar que falta elaborar marcos normativos que evalúen incisivamente la abundante literatura sobre felicidad que inunda librerías y otros espacios comunes. ¿Podemos llamar felicidad a cualquier cosa? La discusión contemporánea corrobora esta inquietud. Una crítica semejante y enfocada a la psicología positiva y la economía de la felicidad la desarrollan Cabanas e Illouz (2019). Pareciera a veces que psicólogos positivos, como Selgiman (2002), se concentran en que la gente pueda alcanzar sus metas sin importar cuáles sean ${ }^{9}$. Del mismo modo, Duncan cree que aún

7 Resuena acá la vieja crítica que recibían los epicúreos, de quienes se decía que reducían la felicidad del ser humano a la de un cerdo y que Mill sintetizó: «Es mejor ser un ser humano insatisfecho que un cerdo satisfecho; mejor ser un Sócrates insatisfecho que un necio satisfecho» (2014, p. 66). Por cierto, ni Mill ni Epicuro igualaron el placer humano al de los cerdos, y Mill representa el más célebre pensador del siglo XIX preocupado por la felicidad como cuestión pública.

8 Para las citas de la Ética nicomaquea de Aristóteles, se utilizará la traducción de Julio Pallí de la Editorial Gredos (1998) con las referencias en el formato clásico entre corchetes para esta y otras obras del autor.

9 Se cita como ejemplo a Martin Seligman, fundador o «padre» de la psicología positiva. «Imagine a un sadomasoquista que se recrea en los asesinatos en serie y obtiene un gran placer con los mismos. Imagine un asesino a sueldo que obtiene gratificación acechando y 
falta trabajar más la conceptualización de la felicidad para que esta pueda efectivamente convertirse en objeto de las políticas públicas (2010). Particularmente, subraya la necesidad de reevaluación ética del concepto para que sea un objetivo político. A su turno, De Prycker comparte esa misma perspectiva crítica (2010). La maximización de la felicidad puede sonar intuitivamente atractiva como agenda social, pero ¿qué significa en términos morales? ¿Podríamos, por ejemplo, aceptar una decisión política que oprime a una minoría pero que maximiza la felicidad global? Con una preocupación similar, y siguiendo una vía paralela a la que se presenta en este artículo, Crespo y Mesurado recurren también a la teoría de Aristóteles para procurar solucionar algunos de los vacíos teóricos y normativos que los críticos detectan (2015). Finalmente, Haybron y Tiberius hacen eco de las interrogantes, pero no acuden a la tradición aristotélica, sino a lo que denominan subjetivismo pragmático para solucionar los vacíos de fundamentación (2015).

El presente artículo acoge las críticas mencionadas y añade las suyas propias. Pero además pretende incorporar la opinión del ciudadano de a pie. El modelo deliberativo de Habermas explica que la legitimidad de las políticas proviene de la discusión amplia con los afectados (1998). Según Habermas, las decisiones y acciones de los gobernantes deben ser formadas desde los debates que suceden en la esfera pública. Aquello que se convertirá en ley y poder administrativo debe venir inspirado por lo que los ciudadanos debaten y consensúan como los mejores argumentos. Se trata de recolectar aportes desde los ciudadanos, la academia y otras fuentes para alimentar el diálogo. En este artículo se analiza, pues, los resultados de la «opinión ciudadana» al menos en los dos extremos socioeconómicos del país. Este resulta un insumo fundamental. El otro aporte proviene de la teoría o academia con la visión aristotélica. ¿Sería posible que eventualmente una institución pública o la misma academia organicen debates amplios con ambos insumos, y otros, para derivar significados y acciones consensuadas? La tarea excede los límites del presente artículo. Sin embargo, se adelanta aquí al menos la puesta en diálogo

matando. Imagínese a un terrorista de Al-Qaeda que estrella un avión secuestrado contra el World Trade Center. ¿Podría decirse que estas tres personas han obtenido, respectivamente, la vida placentera, la buena vida y la vida significativa? La respuesta es "sí". Por supuesto, condeno sus actos, pero por motivos ajenos a la teoría explicada en este libro. Los actos son moralmente despreciables, pero la teoría no es una ley moral ni una visión del mundo, es una descripción. Estoy convencido de que la ciencia es moralmente neutral, pero éticamente relevante. La teoría expuesta en este libro describe qué es la vida placentera, la buena vida y la vida significativa. Describe cómo alcanzarlas y cuáles son las consecuencias de vivirlas. No las prescribe ni tampoco valora ninguna de ellas más que otra desde el punto de vista teórico» (2002, p. 400). En cambio, la tradición filosófica rechazaría tajantemente tal enfoque, como se verá más adelante. 
teórica para delimitar concepciones pertinentes de la felicidad y sus políticas asociadas.

\section{Cuestiones normativas sobre el contenido de la felicidad}

Como se anunció, se espera analizar las respuestas de las entrevistas desde una teoría ética de la felicidad a fin de justificar normativamente las concepciones como las posibles políticas públicas que las promovieran. Para ello se elige la visión eudaimonista de Aristóteles. Pero ¿por qué sería esta relevante en vez de, por ejemplo, la concepción también clásica de los epicúreos o una más bien moderna de los utilitaristas? Sin pretender ser exhaustivos por limitaciones de espacio, conviene señalar la centralidad de algunas ideas Aristóteles en los debates contemporáneos incluso en escuelas tan distintas como la psicología positiva y la economía de la felicidad. Así, la concepción de la felicidad que utilizan más comúnmente las corrientes actuales en los estudios econométricos de la felicidad se reconoce en la tradición aristotélica al menos en sus elementos fundamentales $^{10}$. De todos modos, conviene examinar qué tan fieles son respecto de la eudaimonia aristotélica más allá de declarar su suscripción. Por ejemplo, los reportes más amplios y reconocidos, como el «Informe mundial de la felicidad» (Helliwell, Layard, y Sachs, 2012), promovido por la ONU, declaran suscribir la visión eudaimonista. Ellos utilizan la siguiente pregunta: «después de considerar todas las cosas, ¿cuán satisfecho está usted con su vida como un todo en estos días?» ${ }^{11}$. Esta pregunta evalúa racionalmente la realización de una vida. Satisfacción implica reconocer los objetivos fundamentales y de largo plazo, y su grado de cumplimiento. Un animal no posee ese tipo de objetivos ni puede evaluar racionalmente su logro. Allí habría cierta similitud entre la pregunta con el argumento aristotélico. No obstante, siendo estrictos, no le haría justicia plena al Estagirita, particularmente desde cuestiones sustanciales de la felicidad, como veremos en breve.

La eudaimonia aristotélica puede comprenderse desde su forma, elementos formales, y desde su fondo o forma, elementos materiales o sustanciales. Los aspectos formales se refieren a las propiedades bastante conocidas de la felicidad: perfecta, suficiente, actual -esto es, en acto o actualización constante- y estable, aspectos que en conjunto caracterizan la realización de la mejor vida posible. Primero, la felicidad es el

10 La otra gran etiqueta que aglutina a los estudios contemporáneos se denomina hedonista. Se asocia más a la evaluación de las emociones positivas y negativas.

11 «All things considered, how satisfied are you with your life as a whole these days?». Otras versiones comunes simplemente recortan la pregunta: «all things considered, how satisfied are you with your life?». 
bien más perfecto, y lo es por sí mismo porque no se procura con vistas a conseguir algo más ${ }^{12}$. Segundo, es un bien suficiente, lo cual significa que no requiere de algo más ${ }^{13}$. Uniendo estas dos propiedades se concluye que la felicidad se elige por sí misma, puesto que bienes como las riquezas materiales se persiguen por la felicidad que producen. Pero nadie procura ser feliz para alcanzar dichos bienes. Además, es una actividad, pues lo más perfecto es lo que está en acto y no solo en potencia, esto es, lo que es vale más que lo que puede ser $^{14}$. Por tanto, es desarrollo, acción o realización. Insiste Aristóteles en que el bien humano supremo, como el bien de cualquier otro ente, está en la realización de su función o esencia propia. Para el caso humano, siendo primariamente un ser racional, y cuya razón se sitúa en el alma, sentencia el filósofo que la felicidad es actividad del alma conforme a su virtud ${ }^{15}$. Cuarto, se trata de algo estable durante la realización de una vida. Es un proyecto en largo desarrollo, no un instante. «Porque una golondrina no hace verano» (1998, p. 144 [1098a18-19]). No tendría sentido que el bien mayor sea tan efímero como corresponde a la duración de los placeres corporales que nuestra naturaleza biológica requiere y disfruta. El ser humano es más que un cuerpo sensible.

Ciertamente las propiedades formales, descritas apenas a partir de Aristóteles, ofrecen ya ciertas pistas para evaluar algunos candidatos posibles a ser considerados como la felicidad. En su época él supo criticar los modos de vida más comunes como adecuados o no precisamente desde las propiedades mencionadas. Primer ejemplo, en el mundo de hoy aún mucha gente considera que la felicidad se centra o parte de la bonanza económica. Si el mayor bienestar consiste en la posesión de cuantiosa riqueza, ¿alguien que hereda una fortuna podría considerarse

12 «Ahora bien, al que se busca por sí mismo le llamamos más perfecto que al que se busca por otra cosa, y al que nunca se elige por causa de otra cosa, lo consideramos más perfecto que a los que se eligen, ya por sí mismos, ya por otra cosa. Sencillamente, llamamos perfecto lo que siempre se elige por sí mismo y nunca por otra cosa» (1998, p. 142 [1097a30-35]).

13 «Consideramos suficiente lo que por sí solo hace deseable la vida y no necesita nada, y creemos que tal es la felicidad. Es lo más deseable de todo, sin necesidad de añadirle nada» (1998, p. 143 [1097b14-17]). Aunque suena lógico decir que la felicidad con la superabundancia de bienes es mejor que la felicidad sin tal superabundancia, de todos modos, queda claro que no habría otro bien, en singular, mayor que ella.

14 Tal principio es expuesto en la Metafísica: es más perfecto lo que está en acto (Aristóteles, 1994). Se explica como uno de los atributos del primer motor: si este fuera tal solo en potencia, necesitaría de un agente que lo pusiera en movimiento, que lo volviera motor en acto.

15 «Pero quizás hay no pequeña diferencia en poner el bien supremo en una posesión o en un uso, en un modo de ser o en una actividad. Porque el modo de ser puede estar presente sin producir ningún bien, como en el que duerme o está inactivo por cualquier otra razón, pero con la actividad esto no es posible, ya que esta actuará necesariamente» (Aristóteles, 1998, p. 147 [1098b31-1099a3]). Hacia el final de esta sección se expondrá qué significa la virtud y se verá que la felicidad no se logra mediante cualquier forma de actividad, sino aquella ligada a la razón o virtud propia del hombre. 
abundantemente feliz gracias a su buena suerte? No, porque no hubo actividad propia, y la felicidad es acto. El dinero se puede recibir incluso pasivamente, mientras que la felicidad requiere actividad por uno mismo, ser producto del esfuerzo propio. Segundo, la felicidad tampoco puede consistir en la fama o vivir esperando el reconocimiento de los otros. Puesto que la opinión ajena sobre uno, aunque fundamental para la vida, es esencialmente externa. Si la felicidad reposa en la actividad propia, depende más de uno mismo que de otros ${ }^{16}$. Tercero, otro candidato común puede ser el gozar de placeres físicos, puesto que nuestra constitución biológica, como la de cualquier animal, se orienta naturalmente hacia ellos. Pero todos son breves o efímeros comparados con la extensión de una vida. Ninguno de ellos es estable, sino que pasan rápido, mientras que la felicidad se alcanza vía una actividad permanente o la más constante posible.

La literatura contemporánea de estudios sobre la felicidad, que se suele autocalificar como eudaimonista y emparentada con Aristóteles, ciertamente subraya el desarrollo de una vida satisfactoria como esencia de la misma. Al preguntar los investigadores «¿cuán satisfecho está usted con su vida?», destacan la comprensión de la vida como un proyecto (Helliwell, Layard, y Sachs, 2012). El haber logrado metas trazadas como estudios, matrimonio, desarrollo profesional -entre otros bienes o fines intermedios, en lenguaje aristotélico- permite evaluar racionalmente si se cumplió el proyecto deseado (la felicidad como fin último). Ciertamente diversos aspectos formales desarrollados por Aristóteles se simplifican en esta aproximación. Sin embargo, la distancia mayor respecto a la comprensión del Estagirita se encuentra en el fondo de la felicidad. Para la mayoría de los investigadores lo que cuenta es que la persona se sienta realizada, satisfecha, al margen de cuál haya sido el proyecto vital planteado o desarrollado. Se podría repetir el error de algunas versiones de la psicología positiva ${ }^{17}$. ¿Basta con su realización? No. Se requiere evaluar críticamente si los modos desplegados o los bienes conseguidos son acordes a los elementos aristotélicos u otra teoría que pudiera ofrecer elementos normativos.

Para resolver la cuestión, falta añadir aún los componentes fundamentales y sustanciales. La mejor vida posible para una persona no se puede

16 Aristóteles discutió el caso de los políticos más que el de quienes se consideran famosos en el mundo actual: deportistas, artistas, etc. «Los mejor dotados y los activos creen que el bien son los honores, pues tal es ordinariamente el fin de la vida política». Pero este bien, reconocimiento o buena reputación, no puede ser el central puesto que «radica más en los que conceden los honores que en el honrado, y adivinamos que el bien es algo propio» (1998, p. 136 [1095b22-26]). En contextos latinoamericanos, plagados por escándalos de corrupción, parece irreal afirmar que los mejor dotados se empeñan en la vida política.

17 Ver nota 5 respecto de Seligman. 
igualar a la de cualquier animal porque no tendría en cuenta lo propio o característico del hombre: la razón y la sociabilidad. Primero, en cuanto a la razón, este es el elemento primordial que determinará finalmente cuál es su propia felicidad de acuerdo con la naturaleza humana. De allí que la definición clásica de la eudaimonia aristotélica podría resumirse en el desarrollo o la realización de una vida racional, es decir, conforme a la virtud propia del hombre ${ }^{18}$. El despliegue de un proyecto de vida según la razón se puede realizar en asuntos teóricos o intelectuales (estudiar matemáticas, desarrollar tecnologías avanzadas, gozar de una buena novela u obra de arte, entre otros) o cuestiones de sabiduría práctica (vivir de manera honesta, ejercer la generosidad, procurar la convivencia justa y armoniosa, entre otras actividades). Como señala Aristóteles, las virtudes pueden ser intelectuales -o dianoéticas - y morales —o éticas-; esto es, sirven tanto para pensar bien como para actuar bien. En suma, para evaluar las concepciones de felicidad de las personas reales y el éxito de su persecución, es posible utilizar la virtud humana, además de los elementos formales anteriormente mostrados. Así se trata de evaluar si las concepciones de felicidad se ajustan a la característica humana de vivir desplegando la racionalidad, sea como desarrollo intelectual, sea como sabiduría práctica ${ }^{19}$. Segundo, respecto a la sociabilidad, el ser humano es un animal social. «De todo esto es evidente que la ciudad es una de las cosas naturales y que el hombre es por naturaleza un animal social -zoon politikón-, y que el insocial por naturaleza es o un ser inferior [una bestia] o un ser superior al hombre [un dios]» (2008, p. 50 [1253a2-5]). La razón, lo característico de la vida humana, se desarrolla con otros. Nadie es capaz incluso de aprender el lenguaje, menos aún de pensar, sin la ayuda de

18 «Si, entonces, la función propia del hombre es una actividad del alma según la razón, o que implica la razón, y si, por otra parte, decimos que esta función es específicamente propia del hombre y del hombre bueno, como el tocar la cítara es propio de un citarista y de un buen citarista, y así en todo añadiéndose a la obra la excelencia queda la virtud (pues es propio de un citarista tocar la cítara y del buen citarista tocarla bien), siendo esto así, decimos que la función del hombre es una cierta vida, y esta es una actividad del alma y unas acciones razonables, y la del hombre bueno estas mismas cosas bien y hermosamente, y cada uno se realiza bien según su propia virtud; y si esto es así, resulta que el bien del hombre es una actividad del alma de acuerdo con la virtud» (1998, p. 144 [1098a7-17]). También «nuestro razonamiento está de acuerdo con los que dicen que la felicidad es la virtud o alguna clase de virtud, pues la actividad conforme a la virtud es una actividad propia de ella» (1998 [1098b30-31]).

19 Para ser fieles con la exposición de Aristóteles, habrá que señalar que él considera las virtudes teóricas como superiores a las prácticas. El porqué de dicha valoración se encuentra sobre todo en el Libro X de la Ética nicomaquea, más que en el Libro I, en el cual estamos basando el recuento. El motivo por el que no insistimos en el desarrollo de dicha superioridad en nuestro argumento del cuerpo principal estriba en que él creía que la felicidad suprema de las virtudes intelectuales estaba reservada para unos pocos con ciertos privilegios naturales y materiales. En cambio, el argumento que expondremos en la sección tercera abarca a personas de diferentes condiciones sin suscribir una jerarquía natural. 
otros. Ni siquiera puedo ser «yo» o «alguien» si no es dentro de un orden social como también señalaron más contemporáneamente la psicología de Mead (1968) o la teoría de la autenticidad de Taylor (1994). Se mantiene la teoría de Aristóteles de la necesaria integración comunitaria: primeramente a la familia y la escuela, pero luego a la sociedad.

Si cierto sector de la psicología positiva sostiene que un corrupto o un terrorista pueden ser felices en tanto alcancen sus metas ${ }^{20}$, resulta evidente que esto no sería posible desde la teoría aristotélica apenas presentada. ¿Por qué? Pues no despliegan la virtud ni la sociabilidad. Delincuentes y criminales se encuentran más cerca del vicio — robo, crueldad, irrespeto- que de las virtudes: honestidad, justicia, solidaridad; por tanto, no son racionales, pues lo racional es actuar bien. Además, destruyen o corroen la sociedad a la que se deben. La suya no puede llamarse felicidad.

\section{La felicidad en los extremos sociales del Perú}

Corresponde ahora aplicar estas tesis aristotélicas a los resultados del trabajo de campo. Este incluía tres preguntas abiertas que se sintetizan en las siguientes tablas. Aquellas reflejan las concepciones de felicidad comunes para los jefes de hogar pobres y ricos. Se presentarán progresivamente análisis y conclusiones por cada una de las cuestiones a analizar. La tabla 1 resume la comparación de respuestas respecto de la pregunta «Si pudiera cambiar algo en su vida, ¿qué sería?». No se pregunta por la felicidad directamente, pero sí por algo que se considera valioso de alcanzar u obtener. Cuando las personas respondieron ciertamente expresaron un bien que anhelan, una meta que poseen y desde la cual pueden juzgar ellos mismos su vida como satisfactoria o no.

Respecto de los ítems más altos o sobresalientes, los jefes de hogar más adinerados respondieron «nada» en primer lugar, con 37,19\%; y en el caso de los menos pudientes esa respuesta también ocupó el primero con $21,6 \%$. El dato es llamativo, pues expresa que gran parte de los muy pobres y los muy ricos consideran haber alcanzado un nivel alto de satisfacción, de modo que no desean cambiar nada. No debería interpretarse el dato como señal de resignación, porque quienes tal vez consideraron la imposibilidad de cambiar algo señalaron «No se puede» (dentro del grupo de los pobres corresponde al 2,6\% y $0 \%$ dentro de los ricos). El dato de elevados niveles de satisfacción, sin embargo, contrasta con otros factores destacados particularmente por el grupo de los desposeídos. Formación o educación ocupa el segundo lugar con 19,37\%; muy cercano se ubica 
TABLA 1. ¿Qué desean cambiar los jefes de hogar de distritos muy pobres y muy ricos? (Encuesta FPV 2017)

\begin{tabular}{lcccccc} 
& \multicolumn{2}{c}{ JH pobres } & \multicolumn{2}{c}{ JH ricos } & Dif. \\
Rubro & $\mathbf{n}$ & $\%$ & $\mathbf{n}$ & $\%$ & $\%$ \\
\hline Nada & 116 & 21,6 & 151 & 37,19 & 15,59 \\
\hline Situación laboral (desempleo, rendimiento) & 100 & 18,62 & 32 & 7,88 & 10,74 \\
\hline Formación o educación & 104 & 19,37 & 42 & 10,34 & 9,03 \\
\hline Residencia (lugar y condiciones) & 37 & 6,89 & 6 & 1,48 & 5,41 \\
\hline Familia (familia, estado civil) & 14 & 2,61 & 30 & 7,39 & 4,78 \\
\hline No sabe / No responde & 20 & 3,72 & 33 & 8,13 & 4,41 \\
\hline Malos momentos & 4 & 0,74 & 20 & 4,93 & 4,19 \\
\hline Yo (modo de vivir, personalidad) & 61 & 11,36 & 32 & 7,88 & 3,48 \\
\hline Cuidado del cuerpo (salud, muerte, edad) & 15 & 2,79 & 23 & 5,67 & 2,88 \\
\hline Bienes económicos (carro, casa, dinero) & 31 & 5,77 & 12 & 2,96 & 2,81 \\
\hline No se puede & 14 & 2,61 & 0 & 0 & 2,61 \\
\hline Otros (viajes, religión, etc.) & 21 & 3,91 & 25 & 6,16 & 2,25 \\
\hline & 537 & 99,99 & 406 & 100 & \\
\hline
\end{tabular}

la situación laboral con 18,62\%; y aun significativo es el cuarto puesto para el rubro «yo» («mi modo de ser», «mi personalidad» con 11,36\%). La educación se corresponde con el desarrollo de las virtudes intelectuales y las éticas; además, y por lo anterior, posee otras utilidades como ofrecer mejores perspectivas laborales. Si bien el trabajo constituye la principal vía para salir de la pobreza, no debe ser supeditado automáticamente al fin de poseer más riqueza o bienes materiales, sino también como una actividad racional que desarrolla a la persona, como se mostrará en breve al analizar la tabla 2. Educación y trabajo serían aspiraciones aprobadas en el marco aristotélico. En cambio, el «yo» representa un caso más difícil de evaluar. Expresiones como «cambiar mi modo de ser», o «personalidad», o semejante, fueron algunas de las que se agruparon en este rubro. Estas bien podrían relacionarse con las virtudes éticas, pero habría sido necesaria mayor precisión en las entrevistas para confirmarlo ${ }^{21}$.

21 Aristóteles señalaba que «son tres las cosas que suceden en el alma, pasiones facultades y modos de ser» (1998, p. 167 [1105b19-20]). Dado que las virtudes, como la valentía, la justicia, la moderación u otras, no se reciben espontáneamente, requieren de su cultivo y desarrollo. Las virtudes éticas suponen un esfuerzo consciente por controlar racionalmente las pasiones. Por tanto, las virtudes son «modos de ser» que nos disponen para actuar respecto de las pasiones. Para interpretar con mayor precisión si las respuestas de los entrevistados correspondían al deseo de mejorar la propia virtud, hubiera sido necesario indagar con mayor 
Evaluemos la formación o educación. Los pobres la priorizaron con $19,37 \%$ y los ricos con $10,34 \%$. Pero, más allá del dato estadístico, ¿qué valor le asignan? Según el artículo 13 de la Constitución, «la educación tiene como finalidad el desarrollo integral de la persona humana» (1993), lo cual calzaría muy bien con el espíritu de Aristóteles, como se puede apreciar en los libros VII y VIII de la Política (2008). La educación, sobre todo en sus niveles superiores, provee herramientas para elevar los desempeños laborales. Sin embargo, no debe concebirse solo como útil para algo más, trabajo o ingreso, sino que la educación es un fin en sí mismo, ya que desarrolla al ser humano, idealmente en su integridad, al margen de cualquier beneficio adicional que se pudiera obtener. Hoy parecería que la educación, particularmente la superior, se ha vuelto una mercancía o inversión (Giusti, 2019), mientras que Aristóteles la defendía en tanto que permite que los seres humanos desplieguen su naturaleza. La educación es valiosa porque realiza lo propio y mejor de la persona, su razón, lo cual se identifica con el espíritu del ocio. Para el Estagirita, el ocio supera al trabajo y es más noble que el negocio, que etimológicamente significa «negación del ocio» (Bertelli, 1984; Hernández, 2012)²2. Si trabajar significa dedicarse a una actividad productiva primaria (agricultura, ganadería, etc.), entonces idealmente se realiza para dejar de hacerse ${ }^{23}$. El fin de dicha labor sería lograr medios suficientes para dejar de trabajar y más bien dedicarse al cultivo propio, al tiempo del ocio. El tiempo empleado en el desarrollo de la virtud no posee un fin más allá de él mismo. Por ejemplo, el ocio se ocupa en hacer ciencia por el valor de la ciencia (sin buscar una aplicación tecnológica, sino por saber más sobre cómo funciona el mundo). Lo mismo se señala respecto del escuchar música, leer, desarrollar la cultura, entre otras actividades afines. Se desprende de lo anterior que, entendida en estos términos, la formación, sin negar su utilidad para otros fines, constituye un fin valioso y posible objeto de políticas públicas orientadas a la felicidad, pues directamente desarrolla a las personas.

En el grupo de los jefes de hogar económicamente privilegiados no se aprecia algún rubro apremiante o urgente. El 10,34\% señala la formación

detalle a qué se refieren con «cambiar mi modo de ser». Al momento de la entrevista se registraba afirmaciones simples mientras que el concepto de virtud requiere cierta elaboración. 22 «La vida tomada en su conjunto se divide en trabajo y ocio, en guerra y paz, y de las acciones, unas son necesarias y útiles, y otras nobles. Y en este terreno, es necesario hacer la misma elección que para las partes del alma y sus actividades: que la guerra exista en vista de la paz, y el trabajo en vista del ocio, y las acciones necesarias y útiles en vista de las cosas nobles [...] un hombre debe ser capaz de trabajar y de guerrear, pero más aún, de vivir en paz y tener ocio, y llevar a cabo las acciones necesarias y útiles, pero todavía más las nobles» (2008, p. 441 [1333a31-1333b3]).

23 Párrafos abajo se retomará el tema para explicar en qué sentido el trabajo hoy también puede considerarse un medio para desarrollar la virtud. 
(que era $19,37 \%$ para los desfavorecidos); el 7,88\%, la situación laboral (18,72\% para los pobres); y así sucesivamente. De allí resulta claro que respecto de cambios necesarios en políticas públicas para elevar la felicidad global, que incluye ambos extremos de la pirámide social, la agenda de los pobres debe ser largamente priorizada, pues los pudientes evidencian mayor conformidad. A estos últimos no les urge o preocupa tanto.

Por último, entre los factores menos destacados para ambos grupos aparecen los bienes económicos (automóvil, casa, dinero). Ni siquiera en el caso de los menos privilegiados eran prioridad, sino para solo un $5,77 \%$; peor aún para los prósperos, con un 2,96\%. Algo semejante sucede con los temas relacionados con el cuidado del cuerpo (salud, muerte, envejecimiento). Para los menesterosos era de 2,79\%, y 5,67\% para los pudientes. En lenguaje aristotélico, ¿se estaría mostrando así que los bienes exteriores (riquezas) y del cuerpo (salud) no eran tan significativos como los bienes del alma (formación) al menos como aspiración para ambos grupos? Recuérdese acá una célebre tipología aristotélica: «Divididos, pues, los bienes en tres clases, los llamados exteriores, los del alma y los del cuerpo, decimos que los del alma son los más importantes y los bienes por excelencia, y las acciones y las actividades anímicas las referimos al alma» (1998, p. 146 [1098b12-16]). De todos modos, parece sensato inferir que los bienes materiales por sí mismos no deberían ser prioridad de las políticas públicas. La educación y el empleo, considerados bienes del alma, de los más necesitados parecen para ellos mismos más urgentes que su acceso a bienes materiales.

La tabla 2 muestra los resultados a la pregunta «¿Qué le hace feliz?». Para ambos grupos, la familia y el trabajo ocupan los primeros lugares. La familia fue señalada por el $40,22 \%$ de los menos privilegiados y por el $50,99 \%$ del sector social opuesto. Se le distingue del rubro de la amistad -que incluye entrar en círculos solidarios, la conversación y la camaradería-y que aparece, en cambio, con 3,35\% para los muy pobres y $4,43 \%$ para los muy ricos. Conviene señalar que para Aristóteles, como se explica en el Libro VIII de la Ética nicomaquea, las relaciones familiares pueden ser comprehendidas dentro del preciado bien de la philia, término griego que en español se traduce por amistad y que pierde el amplio sentido original. Para Aristóteles, las relaciones entre padres e hijos, esposos y esposas, parientes, constituían una forma importante de amistad. Sin embargo, apuntaba el Estagirita, los vínculos naturales de la familia pasan a segundo lugar frente a la virtud. La forma más alta de la amistad corresponde a personas que practican la virtud, la cual es cultivada y elevada aún más gracias a los verdaderos amigos, los virtuosos. Esto no significa que los parientes solo puedan ser amistades por vínculos naturales, sino que es 
mejor si estos son acompañados por una relación que promueve la virtud de las partes. Durante mucho tiempo se ha insistido en la familia como lugar privilegiado del afecto y apoyo; no obstante, algunos sostienen que con la llegada del capitalismo las amistades elegidas reemplazan progresivamente los lazos biológicos de la familia (Zaretsky, 1976). Sea que se prioricen las relaciones en la familia, sea que progresivamente se valoran más los vínculos libremente elegidos, queda claro que los ricos y pobres valoran ampliamente las relaciones. Como señaló Aristóteles -y se citó páginas atrás-, el ser humano es un animal social. Los Informes Mundiales de la Felicidad suelen destacar como uno de los determinantes más importantes de aquella al apoyo social al indagar lo siguiente: «Si usted está en problemas, ¿tiene parientes o amigos con quienes contar cuando los necesita?» (Helliwell, Layard, y Sachs, 2012, 2015 y 2017).

Como se aprecia en los libros VIII y IX de su Ética, Aristóteles creía que la amistad cívica — solidaridad con los conciudadanos o la polis- se considera un bien del alma y central para la convivencia y, por lo mismo, para la felicidad general. Las amistades cívicas tienden a sacar lo mejor

TABLA 2. ¿Qué hace felices a los jefes de hogar de distritos muy pobres y muy ricos? (Encuesta FPV 2017)

\begin{tabular}{lcccccc}
\hline & \multicolumn{3}{c}{ JH pobres } & \multicolumn{2}{c}{ JH ricos } & \multicolumn{2}{c}{ Dif. } \\
Rubros & $\mathbf{n}$ & $\%$ & $\mathbf{n}$ & $\%$ & $\%$ \\
\hline Familia & 216 & 40,22 & 207 & 50,99 & 10,77 \\
\hline Salud & 54 & 10,06 & 5 & 1,23 & 8,83 \\
\hline Naturaleza (animales, plantas) & 30 & 5,59 & 2 & 0,49 & 5,10 \\
\hline Otros & 12 & 2,23 & 28 & 6,90 & 4,67 \\
\hline Trabajo & 59 & 10,99 & 62 & 15,27 & 4,28 \\
\hline Religión & 22 & 4,10 & 1 & 0,25 & 3,85 \\
\hline Pasatiempos (deporte, música) & 37 & 6,89 & 17 & 4,19 & 2,70 \\
\hline Prosperidad económica & 24 & 4,47 & 11 & 2,71 & 1,76 \\
\hline (En blanco) & 3 & 0,56 & 9 & 2,22 & 1,66 \\
\hline Tranquilidad & 20 & 3,72 & 9 & 2,22 & 1,50 \\
\hline Todo vivir & 26 & 4,84 & 25 & 6,16 & 1,32 \\
\hline Nada & 10 & 1,86 & 3 & 0,74 & 1,12 \\
\hline Que mi hijo estudie & 6 & 1,12 & 9 & 2,22 & 1,10 \\
\hline Amistad (camaradería, conversación) & 18 & 3,35 & 18 & 4,43 & 1,08 \\
\hline & 537 & 100 & 406 & 100 & \\
\hline
\end{tabular}


de los ciudadanos, el mutuo respeto, la solidaridad, entre otras virtudes. De allí que políticas orientadas al afianzamiento de lazos sociales, tanto a combatir la desconfianza como la inseguridad ciudadana, pueden ser claves en esta línea. La percepción mutua de inseguridad y desconfianza debe considerarse un obstáculo importante para la felicidad. Los Informes Mundiales de la Felicidad (Helliwell, Layard, y Sachs, 2012, 2015 y 2017) no reportan la sensación de desconfianza, pero sí la percepción de corrupción como un determinante significativo. La corrupción ciertamente mella la felicidad social, pues debilita los vínculos cívicos, entre ciudadanos y con las autoridades.

En segundo lugar, aparece el trabajo, el cual representa el 10,99\% para los desvalidos y el 15,27\% para los prósperos. Ambos tipos de jefes de hogar lo observan como parte fundamental de su felicidad, pero recuérdese que, como se ha señalado líneas arriba, para Aristóteles el cultivo de la razón pasaba por el ocio antes que por el negocio o trabajo. Nótese que tanto la concepción del empleo como sus formas han evolucionado en el tiempo (Hopenhayn, 2001). En su época, Aristóteles menospreciaba el trabajo por comprenderlo básicamente como actividad física, propia de animales y esclavos, que requiere fuerza y repetición más que inteligencia. Por ejemplo, el albañil no conoce el porqué de la construcción ${ }^{24}$. El Estagirita no niega la importancia de los oficios manuales para la vida de la polis, pero no es este el telos o fin del hombre ni de la comunidad, que más bien está relacionado con el despliegue de la razón (Borisonik, 2011). Sin embargo, el empleo contemporáneo, al haberse especializado y profesionalizado, requiere estudio, investigación incluso innovación o renovación constante. Ahora constituye una actividad donde se desarrolla en grado sumo al menos ciertos aspectos de la racionalidad. Crear una campaña publicitaria, un producto financiero, un software informático, entre otros, están lejos del oficio manual repetitivo y despreciado por Aristóteles. Como dice Touraine, en el mundo contemporáneo se encuentran tanto empleos en McDonald's como en Microsoft (1999). Si la felicidad aristotélica radica en realizar lo propio del ser humano, su virtud única frente a los animales, el trabajo moderno constituiría una vía adecuada en tanto desarrolla habilidades especializadas y la inteligencia del empleado, y no se le concibe

24 «Y esto porque los unos saben la causa y los otros no. Efectivamente, los hombres de experiencia saben el hecho, pero no el porqué, mientras que los otros conocen el porqué, la causa. Por ello, en cada caso consideramos que los que dirigen la obra son más dignos de estima, y saben más, y son más sabios que los obreros manuales: porque saben las causas de lo que se está haciendo (a los otros, por su parte, [los consideramos] como a algunos seres inanimados que también hacen, pero hacen lo que hacen sin conocimiento» (1994, p. 72 [981a28-981b3]). 
solo como un conjunto de actividades rudimentarias y rutinarias. De allí que las políticas de fomento de empleo y la formación para el mismo pudieran comprenderse también como centrales para la promoción de la felicidad. En esa línea, se puede señalar como ejemplo el democratizar la infotecnología para que no sean solo unos los privilegiados que ven al empleo como fuente de desarrollo. Esta visión del trabajo como realización humana se riñe con otra que lo reduce solo a un modo de ganarse la vida. El desarrollo personal de un oficio produce dinero, pero mucho más que eso. Ese «más» — autoconfianza, dignidad, reconocimiento y, sobre todo, despliegue de la virtud - debe ser central al definir políticas orientadas a la promoción de la felicidad.

Cabe añadir una salvedad a la conclusión anterior. Si se retoma la tesis aristotélica de que las virtudes pertenecen a dos dominios, el teórico o intelectual, el práctico o ético, habría que añadir que ser un profesional exitoso no garantiza la vida virtuosa. Lamentablemente, abundan profesionales que han desarrollado en grado sumo habilidades intelectuales y técnicas propias de su área; pero tal experticia no va acompañada con el progreso de los aspectos éticos, sino que caen en vicios como la corrupción y otras malas prácticas. Publicistas, ingenieros, financistas, muy expertos en sus funciones, pueden desarrollar su profesión inmoralmente. Se escinde así la razón, la virtud y la felicidad misma. Por tanto, el trabajo y sus políticas asociadas no son suficientes para desarrollar la virtud en la ciudadanía. Es menester hacerlas dialogar con políticas educativas, desde los niveles de educación básica hasta la superior o universitaria, orientadas a forjar personas éticas y no solo técnicas.

Otro hallazgo relevante, al menos por el contraste, se relaciona con el medioambiente. La naturaleza en sentido amplio (relación con los paisajes, animales, etc.) cobra valor para los jefes de hogar pobres con 5,59\%; contrariamente, para los ricos alcanza apenas el 0,49\%. ¿Será por el ambiente rural de los primeros? ¿Poseen una visión más amigable de la naturaleza o al menos de los animales de granja (vacas, ovejas) a quienes aprecian y no consideran solo «medios» o «bienes materiales»? Es ampliamente sabido el interés de Aristóteles por el estudio de los animales y las plantas. Se proponía estudiarlo todo, contemplar o teorizar sobre cualquier objeto de la naturaleza: «lgual hay que acercarse sin disgusto a la observación sobre cada animal, en la idea de que en todos existe algo de natural y de hermoso» (2000, p. 74 [645a21-23]). Pero esta apreciación corresponde a un científico más que a un conservacionista o amante de los animales. Le maravilla la naturaleza porque «en las obras de la naturaleza, en efecto, no existe azar sino el para qué de algo, y en grado sumo y el fin para el que un ser está constituido o producido toma el lugar de lo bello» (2000, p. 74 
[645a23-26]). Si bien algunos han calificado al Estagirita como padre de la ecología animal (Bodenheimer, 1954), lo suyo no debe entenderse dentro del quehacer de los animalistas contemporáneos. Por ejemplo, Aristóteles no aceptaría la idea de que el perro es el mejor amigo del hombre. Aquel, como cualquier otro ser viviente no humano, no posee palabra o razón, por lo que se le considera claramente inferior. Ningún animal ostenta las virtudes humanas, la inteligencia o la justicia. Por tanto, al menos en la visión aristotélica, la fuente de felicidad coincide más con el estudio casi enciclopédico de la naturaleza que con una relación de armonía como los ambientalistas modernos proponen. Tal vez la teoría aristotélica requiere una actualización importante en este punto, pues la satisfacción vital hoy debería comprenderse también en relación con una vida sustentable, como lo recuerdan los Objetivos de Desarrollo Sostenible (2015).

La tabla 3 resume los resultados a la cuestión «¿Qué no le hace feliz?». Se indaga, así, por una preocupación o fuente de infelicidad. Conviene destacar una advertencia previa. Esta ha sido la pregunta más difícil de agrupar como se infiere del hecho de que la categoría «otros» ocupe el segundo lugar con $23,46 \%$ para los menesterosos y $24,14 \%$ para sus opuestos. Los entrevistados contestaron frecuentemente con demasiada diversidad y sin repetición. Las respuestas varían desde «no cantar», «salir de compras» y «el tráfico» hasta «el verano» o «la minería». Por tanto, era inviable su agrupación significativa y solo quedaron registradas como «otros». Las conclusiones que se obtengan de esta sección se deben tomar con extrema prudencia.

TABLA 3. ¿Qué no hace felices a los jefes de hogar de distritos muy pobres y muy ricos? (Encuesta FPV 2017)

\begin{tabular}{lcccccc}
\hline \multirow{2}{*}{ Rubros } & \multicolumn{2}{c}{ JH pobres } & \multicolumn{2}{c}{ JH ricos } & Dif. \\
\hline Problemas sociales & $\mathbf{n}$ & $\%$ & $\mathbf{n}$ & $\%$ & $\%$ \\
\hline Enfermedad (propia/familia) & 14 & 2,61 & 112 & 27,59 & 24,98 \\
\hline Soledad (viudez, lejanía familiar) & 170 & 31,66 & 28 & 6,9 & 24,76 \\
\hline Actitudes y sentimientos negativos & 75 & 13,97 & 23 & 5,76 & 8,21 \\
\hline No sabe & 21 & 3,91 & 49 & 12,07 & 8,16 \\
\hline Economía (desempleo, pobreza) & 2 & 0,37 & 23 & 5,67 & 5,30 \\
\hline Conflictos (familiar, vecinal) & 62 & 11,55 & 32 & 7,88 & 3,67 \\
\hline Nada & 29 & 5,4 & 10 & 2,46 & 2,94 \\
\hline Muerte (propia, de familiar) & 21 & 3,91 & 23 & 5,67 & 1,76 \\
\hline Otros & 17 & 3,17 & 8 & 1,97 & 1,20 \\
\hline & 126 & 23,46 & 98 & 24,14 & 0,68 \\
\hline & 537 & 100 & 406 & 100 \\
\hline
\end{tabular}


Como se mencionó respecto de la tabla 2, Aristóteles propone dividir en tres los bienes que nos conducen a la felicidad: los del cuerpo (como la salud), los del alma (como la virtud) y los exteriores (como las riquezas materiales). Sobre esta calificación, se pueden analizar algunas respuestas obtenidas teniendo en cuenta el límite mencionado en el párrafo anterior. Se destacan tres ideas. Primero, los pobres ubican en primer lugar las enfermedades, propias o de un familiar, con $31,66 \%$, mientras que para los ricos el valor es $6,9 \%$. Los desfavorecidos concederían mayor peso a los bienes del cuerpo; pero no necesariamente porque los valoren más, sino porque las enfermedades los merman con mayor gravedad, ya que no cuentan con el adecuado acceso a la salud. Tal debe ser una prioridad también para políticas orientadas a la felicidad. Segundo, los prósperos priorizan los «problemas sociales» con $27,59 \%$, mientras que sus contrarios solo les otorgan el 2,61\%. Los más pudientes señalan preocuparse por la suerte de la sociedad, pero ¿cómo interpretar ese dato? La preocupación por los otros y la solución de los problemas comunes son elementos fundamentales de la amistad cívica — de la que se ha hablado antes-, la cual es también un bien del alma. Sin embargo, la preocupación social expresada por los ricos peruanos podría tratarse, más bien, de su atención a una problemática social que los afecta en primera persona y no a la sociedad en abstracto o al sector pobre en concreto. Precisamente, la inseguridad ciudadana -ilustrada por la delincuencia común- aparece en las encuestas nacionales sobre problemas del país como el gran tema, y particularmente en Lima, donde reside la mayoría de peruanos ricos (RPP, 2018). Tercero, carentes y privilegiados sitúan los temas económicos en cuarto lugar, con porcentajes significativos, $11,55 \%$ y $7,88 \%$, pero sin que se aprecie que los cataloguen como sus primeras preocupaciones. Los bienes exteriores no son prioritarios ni aun para quienes más carecen de ellos. Nuevamente, como se apreció del análisis de la tabla 1, promover la felicidad no debe asociarse con la abundancia de bienes materiales ni siquiera en los sectores más vulnerables.

\section{Conclusiones}

El Estagirita sabía bien que procurar la felicidad de los conciudadanos es un asunto político de primera índole. Sostenía que es más divino lograr la vida buena de todo el pueblo que la de un individuo ${ }^{25}$. Pero la felicidad, bienestar, vida buena, satisfacción vital, y otros términos frecuentemente

\footnotetext{
25 «Pues aunque sea el mismo el bien del individuo y el de la ciudad, es evidente que es mucho más grande y más perfecto alcanzar y salvaguardar el de la ciudad; porque procurar el bien de una persona es algo deseable, pero es más hermoso y divino conseguirlo para un pueblo y para ciudades» (1998, p. 133 [1094b7-10]).
} 
asociados, no deben confundirse con una alegría momentánea fruto de cualquier capricho. Las entrevistas que se han sintetizado han sido examinadas en perspectiva aristotélica precisamente para atender lo que la gente quiere sin perder una perspectiva crítica o normativa. Por ejemplo, no se trata solo de promover una actitud optimista o positiva en la población, como comúnmente se asocia con la contemporánea cultura de la felicidad. Políticas públicas en educación y psicología social para aprender a ser más optimistas podrían ser un paso o una ayuda. Pero son insuficientes, al menos en perspectiva aristotélica, si ser feliz es más que aprender a sonreír todo el tiempo, incluso ante la falta de salud, educación y empleo. Como sugieren Cabanas e Illouz (2019), un gobierno malintencionado podría aprobar tales políticas para el optimismo mientras recorta el gasto social y los servicios del Estado benefactor, que incluyen salud, educación, empleo, entre otros, y decir que eso no es tan importante como saber sonreír ante la adversidad. Nada más lejos de una comprensión aristotélica de la felicidad.

Varias de las conclusiones presentadas en las secciones previas, inferidas a partir de las preguntas abiertas a los jefes de hogar pobres y ricos, concuerdan con las líneas generales de los informes mundiales de la felicidad (Helliwell, Layard, y Sachs, 2012, 2015 y 2017). Dichos informes señalan que promover la educación, el empleo y la salud, así como fortalecer vínculos sociales, son tareas fundamentales. El dinero no lo es todo; la actitud positiva, tampoco. El Informe Mundial de la Felicidad viene señalando que «excepto en los países muy pobres la felicidad varía más con la calidad de las relaciones humanas que con el ingreso» (Helliwell, Layard y Sachs, 2012, p. 91). En esa misma línea, promover la eudaimonia requiere reorientar las políticas públicas o descentrarlas del excesivo interés del que gozó por décadas el crecimiento del PBI o PBN. Se busca que las personas vivan bien. Empleo, salud, educación y soporte social constituyen elementos centrales de la felicidad que las personas reales esperan y la teoría aristotélica respalda.

\section{Contribución de los autores}

Franklin Ibáñez, Pedro Mateu, Javier Zúñiga y Enrique Vásquez Huamán colaboraron en el planeamiento y desarrollo de las encuestas, el análisis de datos, la discusión y redacción del artículo final.

\section{Fuente de financiamiento}

La investigación contó con el financiamiento del Vicerrectorado de Investigación de la Universidad del Pacífico. 


\section{Conflictos de interés}

Los autores declaran no tener conflictos de interés.

\section{REFERENCIAS BIBLIOGRÁFICAS}

Aristóteles (1994). Metafísica. Madrid: Gredos.

Aristóteles (1998). Ética nicomaquea. Madrid: Gredos.

Aristóteles (2000). Partes de los animales. Madrid: Gredos.

Aristóteles (2008). Política. Madrid: Gredos.

Bertelli, L. (1984). La Scholé aristotelica fra norma e prassi empírica. Aion, 6, pp. 97-129.

Bodenheimer, F. (1954). Aristotle the father of animal ecology. Homenaje a Millás-Vallicrosa, 1, pp. 165-181. Barcelona: Consejo Superior de Investigaciones Científicas.

Borisonik, H. (2011). Pensando el trabajo a través de Aristóteles. Astrolabio. Revista internacional de filosofía, 12, pp. 1-8.

Cabanas, E. e Illouz, E. (2019). Hapycracia. Cómo la ciencia y la industria de la felicidad controlan nuestras vidas. Barcelona: Paidós.

Crespo, R. y Mesurado, M. (2015). Happiness economics, eudaimonia and positive psychology: From happiness economics to flourishing economics. Journal of Happiness Studies 16(4), pp. 931-946. DOI: https://doi. org/10.1007/s10902-014-9541-4

De Prycker, V. (2010). Happiness on the political agenda? Pros and Cons. Journal of Happiness Studies, 11(5), pp. 585-603. DOI: https://doi. org/10.1007/s10902-010-9205-y

Duncan, G. (2010). Should Happiness-Maximization be the Goal of Government? Journal of Happiness Studies, 11(2), pp. 163-178. DOI: https://doi. org/10.1007/s10902-008-9129-y

Giusti, M. (2019). El conflicto de las facultades. Sobre la universidad y el sentido de las humanidades. Barcelona y Lima: Anthropos y Fondo Editorial de la Pontificia Universidad Católica del Perú.

Gobierno del Perú (1993). Constitución Política del Perú. Recuperado de https://www.gob.pe/institucion/presidencia/informespublicaciones/196158-constitucion-politica-del-peru 
Habermas, J. (1998). Facticidad y validez. Madrid: Trotta.

Haybron, D y Tiberius, V. (2015). Well being policy: What standard of well being? Journal of the American Philosophical Association, 1(4), pp. 712-733. DOI: https://doi.org/10.1017/apa.2015.23

Helliwell, J., Layard, R. y Sachs, J. (Eds.) (2012). World Happiness Report 2012. New York: The Earth Institute - Columbia University.

Helliwell, J., Layard, R. y Sachs, J. (Eds.) (2015). World Happiness Report 2015. New York: The Earth Institute - Columbia University.

Helliwell, J., Layard, R. y Sachs, J. (Eds.) (2017). World Happiness Report 2017. New York: The Earth Institute - Columbia University.

Hernández, D. (2012). La escuela del ocio: tiempo libre y filosofía antigua. Cuadernos Hispanoamericanos, 747, pp. 77-99.

Hopenhayn, M. (2001). Repensar el trabajo. Historia, profusión y perspectivas de un concepto. Buenos Aires: Norma.

INEI (2015). Mapa de pobreza provincial y distrital. Lima: INEI.

INEI (2018). Informe Nacional. Censos Nacionales 2017: XII de Población, VII de Vivienda y III de Comunidades Indígenas. Lima: INEI.

Mead, G. (1968). Espíritu, persona y sociedad. Buenos Aires: Paidós.

Mill, J. (2014). El utilitarismo. Madrid: Alianza.

OCDE (2013). OECD Guidelines on Measuring Subjective Well-Being. París: OECD Publishing. DOI: http://doi.org/10.1787 /9789264191655-en

ONU (2011). Happiness: towards a holistic approach to development: resolution / Adopted by the General Assembly. Recuperado de http://repository. un.org/handle/11176/291712

ONU (2015). Objetivos de Desarrollo Sostenible. Recuperado de https:// www.un.org/sustainabledevelopment/es/objetivos-de-desarrollo-sostenible/

Platón. (1988). República. Madrid: Gredos.

Prasoon, R. y Chaturvedi, K. (2016). Life satisfaction: A literature review. The Researcher- International Journal of Management Humanities and Social Sciences, 1(2) pp. 25-32.

Rawls, J. (1995). Liberalismo político. Ciudad de México: Fondo de Cultura Económica.

RPP (2018). Ipsos | El 82\% considera que la seguridad debe ser el tema principal en la campaña municipal en Lima. Recuperado de https://rpp. pe/lima/actualidad/ipsos-el-82-considera-que-la-seguridad-debe-ser-eltema-principal-en-la-campana-municipal-en-lima-noticia-1117592 
Seligman, M. (2002). La auténtica felicidad. Barcelona: Ediciones B.

Taylor, C. (1994). La ética de la autenticidad. Barcelona: Paidós.

Ura, K, Alkire, S y Zangmo, T. (2012). GNH and the GNH Index. Oxford Poverty \& Human Development Initiative (OPHI). Recuperado de https://www.ophi. org.uk/wp-content/uploads/Ura-et-al-Bhutan-Happiness-Chapter.pdf

Veenhoven, R. (1997). Advances in understanding happiness. Revue Québécoise de Psychologie, 18, pp. 29-74.

Zaretsky, E. (1976). Capitalism, the family and personal life. New York: Harper \& Row. 